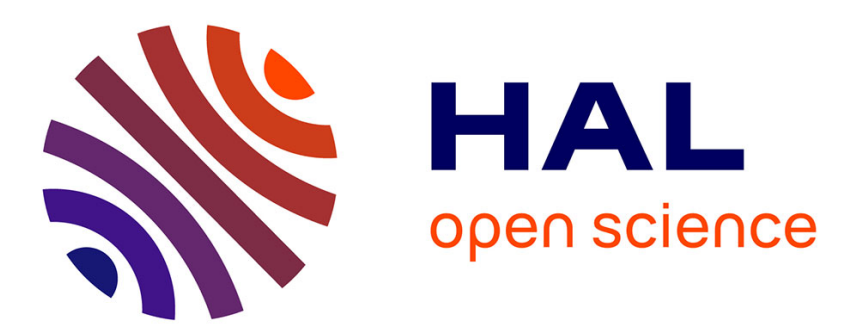

\title{
Oxidation and Reduction Reactions in Spinel Oxides: Influence upon some Physical Properties
}

\author{
P. Perriat, B. Gillot, D. Aymes
}

\section{To cite this version:}

P. Perriat, B. Gillot, D. Aymes. Oxidation and Reduction Reactions in Spinel Oxides: Influence upon some Physical Properties. Journal de Physique IV Proceedings, 1997, 07 (C1), pp.C1-43-C1-46. 10.1051/jp4:1997105 . jpa-00254715

HAL Id: jpa-00254715 https://hal.science/jpa-00254715

Submitted on 1 Jan 1997

HAL is a multi-disciplinary open access archive for the deposit and dissemination of scientific research documents, whether they are published or not. The documents may come from teaching and research institutions in France or abroad, or from public or private research centers.
L'archive ouverte pluridisciplinaire HAL, est destinée au dépôt et à la diffusion de documents scientifiques de niveau recherche, publiés ou non, émanant des établissements d'enseignement et de recherche français ou étrangers, des laboratoires publics ou privés. 


\title{
Oxidation and Reduction Reactions in Spinel Oxides: Influence upon some Physical Properties
}

\author{
P. Perriat, B. Gillot and D. Aymes \\ Laboratoire de Recherche sur la Réactivité des Solides, UMR 5613 du CNRS, BP. 138, 21004 Dijon \\ cedex, France
}

\begin{abstract}
In the first part of the paper, a complete model for oxidation and reduction reactions occurring at low temperatures in finely divided spinel oxides such as $\mathrm{Mn}-\mathrm{Zn}, \mathrm{Mo}$, and $\mathrm{V}$ ferrites is presented. When the Fe-based spinel oxides contain more than one oxidizable cation (for instance $\mathrm{Fe}^{2+}, \mathrm{Mo}^{3+}$ and $\mathrm{Mo}^{4+}$ in $\mathrm{Mo}$ ferrites), it has been demonstrated that each cation oxidizes in a well defined range in temperature in close relation with the cation-oxygen distance of the cation considered. The model involves both thermodynamics and kinetics considerations: thermodynamics involves the minimization of the Gibbs free energy and the kinetics oxidation has been explained on the basis of a diffusion-induced stress effect. Finite element calculations have been developped and applied to compute the features of the reaction in the case of $\mathrm{V}, \mathrm{Mn}-\mathrm{Zn}$ and $\mathrm{Mo}$ ferrites. In these materials, the model enables the evolution with time of oxidation to be explained. In the second part of the paper, the influence of the oxidation and reduction reactions occurring during all the stages of sintering upon both physical and mechanical properties is evidenced.
\end{abstract}

\section{A MODEL FOR LOW TEMPERATURE OXIDATION IN FINELY DIVIDED FERRITES.}

1.1 Relationship between the temperature of oxidation and the mobility of the cations in finely divided ferrites.

The oxidation and reduction reactions in finely divided spinels with the formula Fe3-x $\mathrm{M}_{\mathrm{X}} \mathrm{O}_{4}$ where $0 \leq x \leq 1$ and $\mathrm{M}$ denotes an oxidizable or nonoxidizable cation such as $\mathrm{Mn}$ [1], $\mathrm{V}$ [2], Mo [3], $\mathrm{Zn}$ [4], Al [5], $\mathrm{Cr}$ [6] and Ti [7] have been widely investigated. Within the stability range of the spinel, such reactions consist of a change of the cation to anion ratio, leading to the composition Fe3-x $\mathrm{M}_{\mathrm{X}} \mathrm{O}_{4}+\delta$ where $\delta$ denotes the deviation from stoichiometry ( $\delta>0$ for oxidation and $\delta<0$ for reduction). To model the oxidation of $M^{n+}$ to $M^{(n+m)+}$, when $M^{n+}$ can be oxidized, both thermodynamics and kinetics have to be considered [8]. Thermodynamics gives the fraction of the $M^{n+}$ cations to be oxidized as a function of the temperature and the oxygen partial pressure, and kinetics describes the process for such an oxidation. The transport processes within the particles involves five different types of processes [9]: (i) transport processes in the gas phase, (ii) oxygen transfer at the solid/gas interface, followed by (iii) a dissociation into $O$ atoms and by (iv) an incorporation of $O$ into the lattice with a change in the valence states and a creation of vacancies and (v) transport processes within the particles. At low temperatures, below $600^{\circ} \mathrm{C}$ and for high oxygen partial pressure $\left(\mathrm{pO}_{2}>40 \times 10^{2} \mathrm{~Pa}\right)$, transport within the grain is rate controlling and thermodynamic equilibrium is established during oxidation between the surface and the gas phase far away from the grain. Transport within the grain consists of the relaxation of the vacancies which are created during the incorporation of $O$ into the lattice and oxidation in finely divided ferrites must then be analysed as a vacancy diffusion-controlled process obeying the usual Fick's equations. When the Fe-based spinel contain more than one oxidizable cation, the process of oxidation of each oxidizable cation, $M$, involves some diffusion of vacancies into the sample counterbalanced by outward cation diffusion. In particular, motion of some $M$ cations from the bulk to the surface of the particle is required. Therefore, each cation oxidizes in a well defined range in temperature where its mobility becomes significant. Since the mobility of each species is inversely proportional to the different forces which maintain this species in a defined position, it is possible to relate these forces to the metal-oxygen distances [10]. The cationoxygen distances extracted from large numbers of crystal-structure determinations are given by Poix's assumptions [11] concerning the improved bonding rule of Pauling [12] and are reported in Figure 1. They depends on both the valence and the location of the cations in accordance with covalent bonds in tetrahedral (A) sites shorter than electrovalent bonds in octahedral (B) sites [13]. The data of metal-oxygen distance and temperature oxidation in Figure 1 are reliable in indicating trends, but not very reliable in giving absolute values, owing to the inevitable distribution in particle sizes and shapes on the one hand and to the relative stretching force constants of the bonds, which depend on numerous factors in the case of transition metals [14] on the other hand. However, within the available precision, the oxidation temperature peak data is inversely related to the cationoxygen distance, except conceming the cation $\mathrm{Mo}^{3+}$. Maybe this can be explained by the fact that the cation-oxygen distance of $\mathrm{Mo}^{3+}$ is somewhat uncertain since it is very recently that this distance has been obtained for the first time by Mo K-EXAFS [15]. 


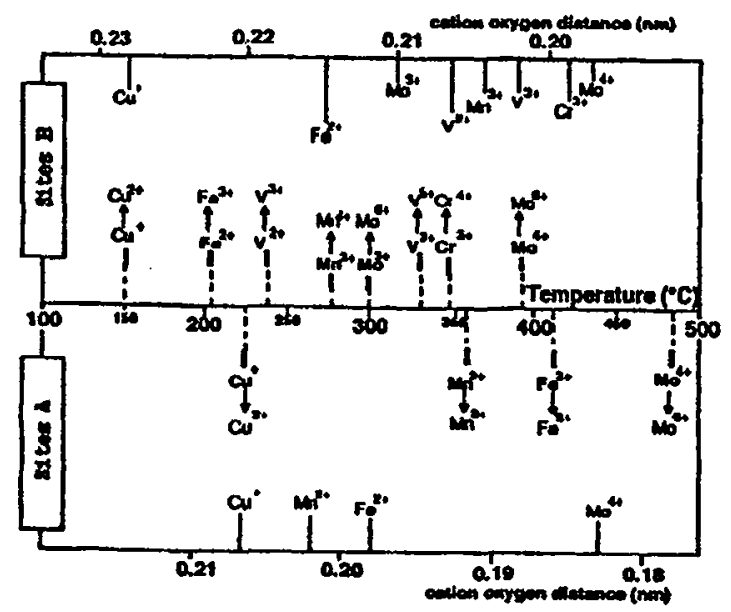

Figure 1: Correlation between the temperature of oxidation of some cations and the cation-oxygen distance for A and B sites.

\subsection{A diffusion-induced stress model}

Classical models related to atomic diffusion via point defects are not able to explain completely the kinetics of oxidation which are experimetally observed in finely divided ferrites at low temperatures. For instance, in the case of a Mo ferrite, Figure 2 shows that the experimental data relative to the oxidation of the $\mathrm{Mo}^{3+}$ cations and a fit of these data obtained from a diffusion model obeying the Fick's laws and based on a constant chemical diffusion coefficient are not in good agreement. This material was prepared using the following chemistry route [16]: (i) precipitation of the mixed oxide, by adding a solution of $\mathrm{Fe}^{2+}, \mathrm{Fe}^{3+}$ and $\mathrm{Mo}^{5+}$ chlorides to an alkaline medium, (ii) calcination of the precipitate up to $600^{\circ} \mathrm{C}$, (iii) reduction under a $\mathrm{N}_{2}(83.7 \%)-\mathrm{H}_{2}(7.3 \%)-\mathrm{H}_{2} \mathrm{O}(9 \%)$ mixture at $600^{\circ} \mathrm{C}$ in order to obtain a ferrite with a spinel structure close to stoichiometry, (iv) quenching under the same $\mathrm{N}_{2}-\mathrm{H}_{2}-\mathrm{H}_{2} \mathrm{O}$ mixture. The shape of the powder grains observed using electronic microscopy is spherical with a mean diameter of $45 \mathrm{~nm}$. From $X$-ray diffraction analysis, infrared spectroscopy and quantitative derivative thermogravimetric analysis, the stoichiometric compound has been found to contain several oxidizable cations: $\mathrm{Fe}^{2+}$ on both $\mathrm{A}$ and $\mathrm{B}$ sites and $\mathrm{Mo}^{3+}$ on $\mathrm{B}$ site [3]. The oxidation reaction of $\mathrm{Mo}^{3+}$ to $\mathrm{Mo}^{6+}$ was studied in a Setaram MTB 10-8 microbalance under pure oxygen with a pressure of $2.2 \times 10^{4} \mathrm{~Pa}$. The powder was spread out in a Pt crucible so that the phenomenon could be analysed as identical independent oxidations of each particle with a radius equal to the average one.
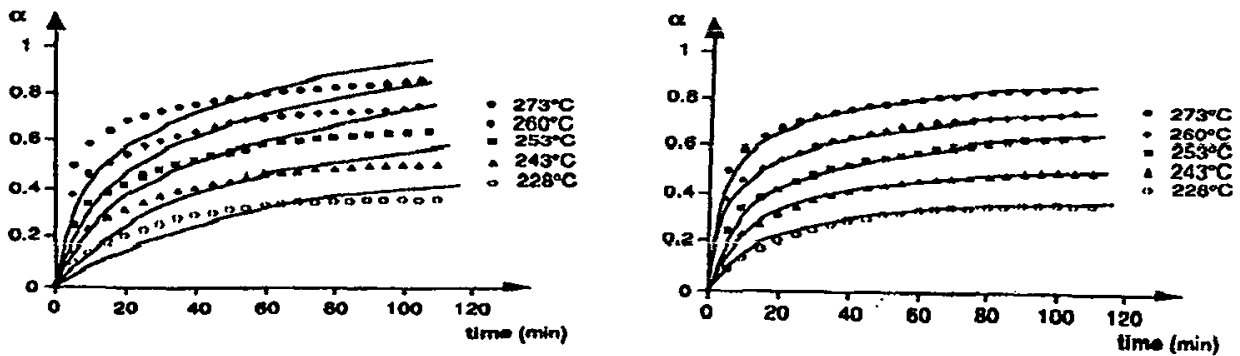

Figure 2: Evolution of the degree of reaction, $\alpha$, with time for isothermal $\mathrm{Mo}^{3+}$ oxidation under pure oxygen with a pressure of $2.2 \times 10^{4} \mathrm{~Pa}$ in the case of a $\mathrm{Fe}_{2} .5 \mathrm{Mo}_{0.5} \mathrm{O}_{4}$ powder with a mean diameter of $45 \mathrm{~nm}$. Left, comparison of experimental data (the points) and a fit of these data obtained from a diffusion model based on a constant chemical diffusion coefficient (----). Right, comparison of experimental data (the points) and of curves obtained taking into account the effect of the stresses (--.--).

In Figure 2, $\alpha$ is the normalized quantity measuring the degree of the oxidation reaction: $\alpha=0$ at the beginning of the reaction and $\alpha=1$ at the end of the reaction. Such an oxidation phenomenon has then been explained on the basis of very significant stresses generated in the particles by the chemical gradient induced during the oxidation [17]. Indeed, the oxidation generates a composition gradient in the bulk of the grain: within each particle, the deviation from stoichiometry, $\delta$, is higher on the surface than in the bulk. Consequently, the oxidized cations and the vacancies are located near the surface, while the low valency cations predominate in the bulk of the grain. Thus the lattice parameter has to vary continuously in the particle, leading to coherency 
stresses. A reaction mechanism coupling the chemical and the mechanical effects has been proposed, by considering that the chemical diffusion coefficient is given by the relation $D=D_{0} \exp \left(-\frac{E_{a}^{\prime}+p_{a}}{R T}\right)$ where $D_{0}$ is a pre-exponential factor, $E_{a}^{\prime}$ an activation energy, $\mathrm{V}_{\mathrm{a}}$ an activation volume [18] and $\mathrm{p}$ the isostatic pressure evaluated from the stress tensor. This model has been used to compute the features of the reaction by the finite element method. In the case of molybdenum ferrites, Figure 2 shows that it enables the evolution with time of oxidation to be explained. Assuming that Young's modulus is equal to $10^{6}$ $M P a$, we find that $D_{0}=(1.6 \pm 0.1) 10^{2} \mathrm{~m}^{2} \mathrm{~s}^{-1}, \mathrm{E}_{\mathrm{a}}^{\prime}=(233 \pm 5) \mathrm{kJ} \mathrm{mol}^{-1}$ and $\mathrm{V}_{\mathrm{a}}=1.1 \Omega$ /diffusing vacancy where $\Omega$ is the atomic volume of the diffusing cations. $\mathrm{V}_{\mathrm{a}}$ is consistent with the activation volumes for self-diffusion in pure metals and binary alloys, which are determinated from isothermal anneals under various hydrostatic pressures, and generally lies between 0.3 and $1 \Omega$ [19].

\section{INFLUENCE OF OXIDATION AND REDUCTION REACTIONS AT LOW TEMPERATURES UPON SOME PHYSICAL PROPERTIES}

\subsection{Infuence of oxidation and reduction reactions upon sintering}

During the rise in temperature for sintering of cores, the oxidation and reduction reactions occurring between 150 and $1000^{\circ} \mathrm{C}$ have a strong influence upon both the grain growth and the densification. For instance, Figure 3 evidences the correlation between the oxidation and reduction reactions and the shrinkage in $\mathrm{Mn}-\mathrm{Zn}$ ferrites with formula $\mathrm{Mn} 0.519 \mathrm{Zn}_{0.354} \mathrm{Fe}_{2.127} \mathrm{O}_{4+} \delta$ during linear experiments with a rate of $2^{\circ} \mathrm{C} / \mathrm{min}$ under air. Two raw powders have been studied: one is stoichiometric $(\delta=0)$ and is denoted "reduced powder"; the other which has been annealed under air at $600^{\circ} \mathrm{C}$ in order to obtain a large $\delta$ is denoted "oxidized powder". The two powders have been ball-milled in an attritor for different times in order to obtain different specific areas measured using the BET method. For the reduced powder, Figure 3 shows that large oxidation and reduction reactions are observed below $600^{\circ} \mathrm{C}$ whereas, for the oxidized powder, only a significant reduction above $700^{\circ} \mathrm{C}$ can be noticed. Moreover for the reduced powder, the oxidation reaction depends on the specific area. A relatively large shrinkage of about $5 \%$ can be attributed to the oxidation and reduction reactions at low temperatures below $600^{\circ} \mathrm{C}$ since this one is observed only for the reduced powder. Such a correlation between the reactions and the densification of the material is of great importance for the ferrite manufacturer, because it explains the cracks which appear during the first stage of sintering: indeed, since the oxidation reactions are inhomogeneous in a core (due to some gradients of temperature and oxygen partial pressure), they lead to strains and stresses which, at low temperatures, can not be released by plastic flow and may lead to cracks. This is coherent with previous experimental data [20] where cracks were observed for the "reduced powder" but not with the "oxidized" one.

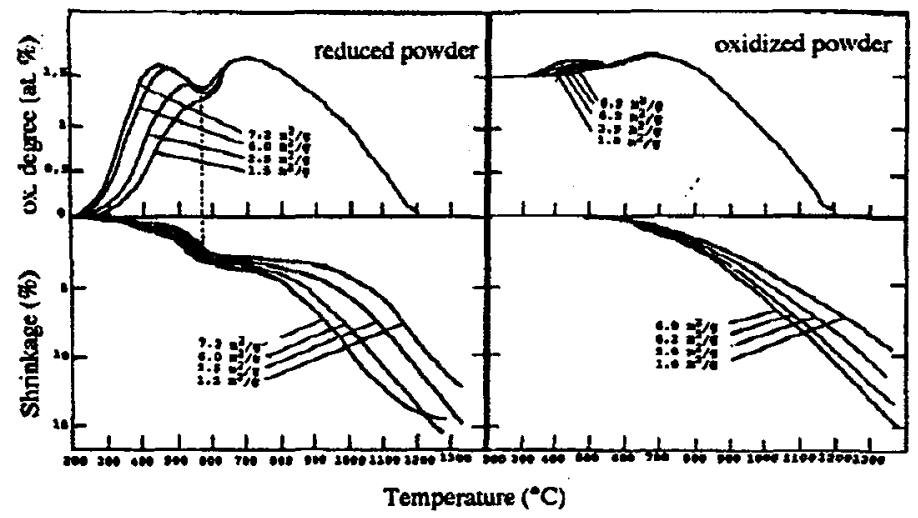

Figure 3: Correlation between the oxidation and reduction reactions and the densification in $\mathrm{Mn}-\mathrm{Zn}$ ferrites.

\subsection{Influence of oxidation reactions upon the coercivity}

In the case of powders or thin films of spinel oxides containing also some Co cations, the magneto-optical properties depends on the oxidation reactions [21,22]. For instance, in $\mathrm{Mn}$ ferrites containing Co, Figure 4 shows the strong correlation between the oxidation reactions and the evolution of the coercivity. The upper part of the figure shows the rate of oxidation obtained from derivative thermogravimetric analysis during linear heating experiments with a rate of $2^{\circ} \mathrm{C} / \mathrm{min}$. Three successive oxidations can be observed, those of the $\mathrm{Fe}^{2+}, \mathrm{Mn}^{3+}$ and $\mathrm{Mn}^{2+}$ cations. The coercivity is measured at room temperature after the same linear heating experiments and quenching at different temperatures. Previously, the increase in coercivity was attributed to the creation of a directional order $[23,24]$ linked to the reorganization of Co ions enhanced by high contents of vacancies. However an additional interpretation can be proposed to explain this phenomenon. Since the anisotropy depends on a combination of both the magnetostriction and the stresses, the increase in coercivity may be explained by an increase of the magnetostrictive properties due to the presence of $\mathrm{Co}$ ions and the significant stresses generated during the oxidation reaction. This explanation is 
justified by the fact that the maxima of coercivity corresponds to those of the rate of oxidation, when the stresses generated by the reaction are the more important.

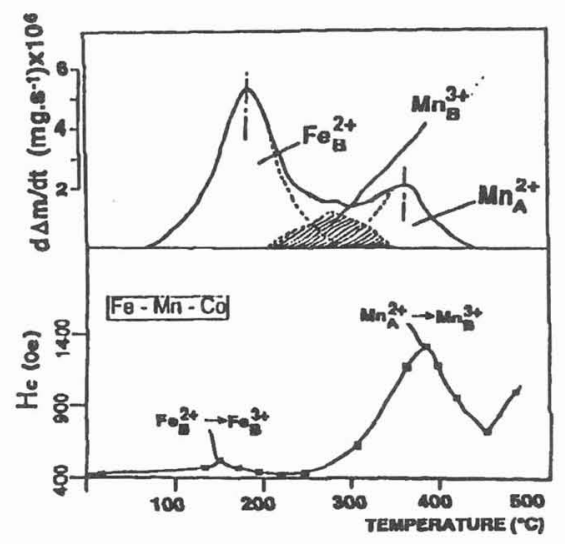

Figure 4: Correlation between the oxidation reactions in $\mathrm{Mn}$ ferrites containing Co and the coercivity.

\section{CONCLUSION}

A complete model for oxidation and reduction reactions at low temperatures has been described. It gives the complete calculation of a diffusion mechanism involving the stresses generated during the reaction and presents also the principles explaining why each cation oxidizes in a well defined range in temperature. Collecting of data about numerous spinel oxides is given and explained by involving the cation-oxygen distance. The influence of the oxidation and reduction reactions upon some physical properties is also emphazised : mechanical properties during sintering, coercivity for magneto-optical applications.

\section{References.}

[1] Gillot B., El Guendouzi M., Tailhades P. and Rousset A., Reactivity of Solids 1 (1986) 139-152.

[2] Nohair M., Perriat P., Domenichini B., Gillot B., Thermochim.Acta 244 (1994) 223-234.

[3] Domenichini B., Gillot B., Bouet L., Tailhades P., Rousset A., Perriat P., Solid State Ionics 58 (1993) 61-69.

[4] Gillot B., Benloucif R.M., Rousset A., Mat.Res. Bull. 16 (1981) 481-489.

[5] Gillot B., Tyranowicz J., Rousset A., Mat.Res. Bull. 10 (1975) 775-782.

[6] Gillot B., Ferriot J.F., Dupré G., Rousset A., Mat.Res. Bull. 11 (1976) 843-848.

[7] Gillot B., Jemmali F., Clerc L., Reactivity of Solids 2 (1986) 95-103.

[8] Perriat P., Metallurgy and Foundry Engineering 20 (1994) 49.

[9] Barret P., Séminaires Chim. Etat Sol (Masson et Cie, Paris, 1974 ) Vol. 8, pp. 243.

[10] Gillot B., J. Solid State Chem. 113 (1994) 163-167.

[11] Poix P., C.R. Acad. Sci. Paris 268 (1969) 1139.

[12] Pauling L., The nature of the chemical bond (Cornell Univ. Press, Ithaca, New York, 1960).

[13] Goodenough J.B., Loeb A.L., Phys. Rev. 98 (1955) 391-408.

[14] Husson E., Repelin Y., Rev. Chim. Miner. 22 (1985) 24.

[15] Bouet L., Tailhades P., Rousset A., Kannan K.R., Verelst M., Kulkarni G.U., Rao C.N.R., J. Solid State Chem. 98 (1992) 123.

[16] Bouet L., Tailhades P., Rousset A., Gillot B., C.R. Acad. Sci. 312 (1991) 1507.

[17] Perriat P., Domenichini B., Gillot B., J. Phys. Chem. Solids, to be published.

[18] Nachtrieb N.H., Weil J.A., Catalano E., Lawson A.W., J. Chem. Phys. 29 (1952) 1189-1197.

[19] Adda Y., Philibert J., La diffusion dans les solides (Institut National des Sciences et Techniques, Saclay, 1966 ) p.814.

[20] Perriat P., Abouaf M., "Oxidation and reduction reactions/mechanical strength relationships in $\mathrm{Mn}-\mathrm{Zn}$ ferrites", Euroceramics, (Elsevier Applied Science, Amsterdam, 1989), p. 237.

[21] Tailhades P., Sarda Ch., Mollard P., Rousset A., J. Mag. Mag. Mater.,104-107 (1992) 969-970.

[22] Bendaoud R., Tailhades P., Fert A.R., Bertrand D., Redoules J.P., Rousset A., IEEE Trans. Magn., VOL. MAG-23, N0 6 (1987) 3869-3873.

[23] Neel L., J. Phys. Rad. 15 (1954) 225-239.

[24] Mollard P., Tailhades P., Rousset A., IEEE Trans. Mag. MAG-26 (1990) 241-243. 